\title{
Psychic Neuronal Hypersynchronies: A New Psychiatric Paradigm?
}

\author{
Javier Alvarez-Rodriguez \\ Servicio de Psiquiatría, Complejo Asistencial Universitario, León, Spain \\ Email: jar1950@hotmail.com
}

Received 27 June 2014; revised 13 August 2014; accepted 28 August 2014

Copyright (C) 2014 by author and Scientific Research Publishing Inc.

This work is licensed under the Creative Commons Attribution International License (CC BY). http://creativecommons.org/licenses/by/4.0/

c) $\underset{\mathrm{EY}}{\mathrm{B}}$ Open Access

\section{Abstract}

This paper deals with certain psychic automatisms that appear suddenly in the consciousness of the subject in a passive or automatic way and that usually are diagnosed as psychiatric symptoms or manifestations of an epileptic partial seizure. These mental automatisms are described in many writings by mystics, philosophers, literates, composers, and many different great artists and creators from human history, but they did not confer any pathological value on these experiences. The analysis of the epileptogenic activity gives us arguments to propose that these automatic experiences are due to neuronal circuits physiologically adapted to fire in a hypersynchronous way. With these data we enunciate an innovative hypothesis: these psychic experiences are manifestations of an adaptive neuronal network for which we propose the term psychic hypersynchrony. Finally, we discuss the consequences of this hypothesis, especially in the epileptic, psychiatric, and neuropsychopharmacologic fields.

\section{Keywords}

Glutamate Hypothesis of Schizophrenia, Kindling, Learning, Long Term Potentiation, Memory, Mysticism, Neuropsychopharmacological Drugs, Partial Seizures, Reflex Epilepsies

\section{Introduction}

This research deals with a form of cerebral functioning named neuronal hypersynchrony, a process that involves the initial depolarization of a great number of neurons at the same time, generating a spontaneous epileptiform discharge.

This hypersynchrony has been traditionally associated with epilepsy and it is interpreted as an epileptic activity. In this regard, it is necessary to remember Hughlings Jackson's definition of epileptic seizure: "An occasional, sudden, excessive, rapid and local discharge of grey matter" [1]. According to this definition, the most typical feature of an epileptic seizure is the excessive number of neurons that synchronize to depolarize at the 
same time, that is, an excessive synchrony, or hypersynchrony.

In the last three decades there have appeared numerous clinical, pharmacological, and physiological evidences that allow hypothesizing about the existence of neuronal hypersynchronies that are the expression of an adaptive functioning of certain areas of our brain [2].

This paper deals with a specific kind of adaptive hypersynchrony that occurs basically in limbic structures and causes automatic psychic experiences which, until now, had been diagnosed as psychic manifestations of simple partial seizures (SPSs), when an EEG record made it possible, or as psychiatric symptoms of different psychiatric disorders. As is well known, simple partial seizures are characterized by a preserved consciousness, unlike complex partial seizures, in which consciousness is impaired consciousness, and generalized epileptic fits, in which consciousness is abolished.

We propose to term this specific hypersynchrony psychic hypersynchrony $(\mathrm{PH})$ in order to clearly and distinctly differentiate it from an epileptic activity, since this one has a pathological connotation.

\section{Methodology}

This proposal of the existence of a cerebral PH as an adaptive function of the human brain is a result of previous researches, which emerged from concatenated manner until finally converging in this hypothesis. The scientific methodology consisted of bibliographic searches on specific issues of each investigative phase. Dozens of concepts related to each of these matters were tracked in journals indexed in Pubmed, and in the most important specific books about the subjects.

The research process involved the following steps in chronological order:

1) Interrelations and overlaps between melancholic depression and the passive purification stage during the mystical process, with specific references to the writings of St. John of the Cross. The result of this research was the book "Mística y depresión: San Juan de la Cruz" (Mysticism and depression: St. John of the Cross) [3], which contains all reviewed bibliography.

2) From that first investigation came out a second hypothesis which proposed that the unusual experiences related by mystics are superimposed to psychic experiences of SPSs, although they didn't attribute any pathological value to them but merely interpreted the experiences as purifying tests sent by God. The result of this second investigation was the book "Éxatsis sin fe" (Ecstasy without faith) [4], which contains the reviewed literature.

3) The third hypothesis concerns the qualitative traits of epileptic consciousness during SPSs, a question that retakes the old concept of aura [5] [6].

4) The fourth step contains the detailed description of the most frequent psychic automatic experiences that appear in SPSs, which are curiously the same that appear in the writings of mystics, and have also identical phenomenological features [7].

5) The next section contains psychic automatisms caused by reflex epilepsies, which often appear as personal experiences not only in the writings of mystics but also in texts of many philosophers, artists and scientists that never conferred them any pathological meaning. Even more, this phenomenology-especially the one relating to musicogenic epilepsy_appears regularly in most of the people. So, it is difficult to keep on assigning any epileptic connotation to it.

6) The seventh section contains a detailed study of the concept epileptogenesis in the sense given to the term by Sloviter [8].

All the evidences exposed in these research steps lead to the final hypothesis of the existence of a PH of adaptive nature.

\section{Results}

In terms of results, we now detail the arguments and evidence found to support and/or validate the hypothesis proposed in each stage, including the final hypothesis of $\mathrm{PH}$.

\subsection{Interrelations between Melancholic Depression and the Mystical Process}

The study began with the analysis of the relationships between mysticism and depression in the writings of St. John of the Cross, a Spanish Golden Age monk, considered by many authors the best Spanish poet at the highest point of Christian mysticism [3]. In his book "Dark Night of the Soul", he describes stages of intense psycho- 
motor inhibition during which he experiences psychic grief similar to the symptoms of melancholic depression, although he interpreted that as purifying trials sent by God [9].

Interspersed with these stages of suffering, St. John of the Cross describes others stages of psychomotor exaltation in which the experiences are just the opposite in nature: sensations of self-fulfillment and well-being reaching the extremes of beatific ecstasy. This alternation of depressive and expansive states reminds us of a bipolar disorder [10].

\subsection{Overlapping of Extraordinary Mystical Experiences and Psychic Manifestations of SPSs}

As we studied deeper the writings of the Spanish mystic we discovered another set of psychic symptoms that appear in his mind suddenly and automatically, as crises of depersonalization or derealization, visual and auditory hallucinations, primary delusional experiences, confusional states, etc. This motley and polymorphic collection of symptoms appearing in the same person leads us to think about a hypersynchronous neuronal activity, more specifically about SPSs with psychic content.

Furthermore, many other Christian mystics describe similar psychic symptoms appearing suddenly and automatically in their minds, suggesting a hypersynchronous activity. For example, Saint Ignatius of Loyola, the founder of the Society of Jesus, describes in his autobiography frequent visual hallucinations with form of a serpent with glittering eyes, phenomenon that is accompanied of an indescribable joy at the sight of this object [11].

We also find these automatic experiences suggesting SPSs of psychic content in many other Christian mystics: Saint Paul, Saint Augustine, Hildegard of Bingen, John Tauler, Henry Suso, Angela of Foligno, etc. We discovered that some of these Christian mystics had already been researched regarding the possibility that they suffered epilepsy: Saint Paul [12], Saint Ignatius of Loyola [13], and Saint Teresa of Ávila [14], but there were no scientific studies about the possible epileptic pathology of the others.

Therefore, it was necessary to carry out a second investigation about mysticism and epilepsy with a thorough study on epilepsy, and specifically about its psychic manifestations. This analysis implied an extensive review of psychic experiences that are present in SPSs. A second monograph, entitled "Éxtasis sin fe" (Ecstasy without faith), was the fruit of this second investigation [4].

\subsection{Phenomenology of Epileptic Consciousness and Concept of Aura}

In order to get an adequate comprehension of the quality of consciousness during a SPS, first it is necessary to analyze in detail the concept of aura. The International League against Epilepsy states that "aura is equivalent to a SPS involving subjective sensory or psychic phenomena only" [15].

By contrast, the concept of aura was completely different for classical authors, neurologists, and psychiatrists alike, who interpreted aura as the psychic experience indicating that a seizure has begun, and therefore, that the normal state of consciousness during wakefulness had been replaced by epileptic consciousness [16] [17]. Probably the most forthright author in this regard was the famous British neurologist Samuel Kinnier Wilson, known for the eponymous Wilson's disease. He literally states, in his Modern Problems in Neurology that "aura is nothing else than the first conscious indication of the commencement of a process that is about to exteriorize itself by signs of the physical series, though it belongs to the psychic series" [16]. Therefore the aura is the psychic experience occurring as a consequence of the triggering of a seizure in which consciousness is changed but still preserved.

We will follow the Ey's chapter on epilepsy [17] and our previous papers on this matter [5] [6] to describe the psychic features that define the quality of aura or epileptic consciousness:

1) Suddenness: epileptic consciousness always starts suddenly and unexpectedly.

2) Timeless nature: the events occurring during aura seem to take place outside time.

3) Automatic nature: aura bursts passively into the consciousness, and unconnected with the subject's will, who contemplates what happens on his mind as an astonished onlooker.

4) A narrowing of consciousness: the subject lays aside the outside world and focuses the attention on the psychic manifestation occurring in the mind, so the experience has a tone of extraordinary clarity, which can even form the illusion of wonderful illumination.

5) Strangeness of the experience: the extraordinary clarity and the automatic nature confer a typical strangeness to the experience, which sometimes is perceived as perplexity by an external observer. 


\subsection{Most Frequent Psychic Experiences That Appear in SPSs and in Mystic Writings}

After delimiting the characteristic features of epileptic consciousness we are ready to describe the most frequent psychic experiences occurring during PSs:

1) False memory or déjà vu: this is "a paroxysmal feeling of familiarity which can be found in no less than half the normal population, but which just as easily can be conceived as a partial seizure" [18].

2) Sudden experiences of depersonalization and derealization, which John Hughlings Jackson interpreted as a manifestation of the dreamy state [18].

3) Panic attacks: there are numerous researches suggesting an interweaving of panic and epilepsy and, although there is still no consensus about the epileptic nature of panic attacks, there is a growing body of evidence pointing to this direction [19] [20].

4) Sudden and brief crises of severe psychomotor inhibition and depression, with different authors postulating that this kind of depressions share common pathogenic mechanisms with epilepsy [21]-[23].

5) Exaltation or manic crises, often in the form of ecstasy with feelings of well-being close to bliss [24] [25].

6) Alternation of the two states described before as an expression of repeated PSs, which makes impossible to distinguish the epileptic discharges from a manic-depressive sate (Ey, 1954). Curiously enough, recent and interesting reviews have appeared that defend the existence of pathogenic mechanisms shared by epilepsy and the bipolar disorder [26] [27].

7) Ictal hallucinations, alone or coexisting with delusions, that suggest the clinical picture of a schizophreniclike psychosis. There are a number of investigations defending the epileptic nature of these syndromes [28][30].

When in the mystical writing prevails attacks of melancholic depression and/or mania, the description resembles a major depression and/or bipolar disorder. But, when the mystical process contains predominantly hallucinations and/ delusive cognitions, the description simulates an unspecific psychosis and/or a schizophrenia-like psychosis.

Surprisingly, many other non-religious writers have described similar experiences. Philosophers such as Plotinus, St. Augustine or Nietzsche; painters like William Blake or Van Gogh; and novelists like Dostoyevsky, Marcel Proust, or Hermann Hesse have all left proof of their personal automatic experiences, although none of them considered them pathological. For example, the philosopher Augustine of Hippo (354-430) describes in his Confessions an episode during which he heard the voice of a boy or a girl, while experiencing an automatic access of joyful tears [31].

With the information available so far we have two important hints that allow us to hypothesize that these extraordinary experiences are not due to epileptic hypersynchrony but to an adaptive psychic hypersynchrony of our brain:

1) Mystics, artists, and philosophers do not assign any pathological value to these irresistible and vivid automatisms.

2) Some of the manifestations that epileptologists consider the expression of psychic SPSs are so common that many of us have experienced them, for example déjà vu, or false memory.

\subsection{Psychic Automatisms in Reflex Epilepsies}

\subsubsection{Concept of Reflex Epilepsy}

The review on reflex epilepsies [32] in which seizures are caused by exposure to a specific stimulus will provide new elements to strengthen our emerging hypothesis of an adaptive neuronal hypersynchrony.

The two most common types are the photosensitive epilepsy [33] where attacks are brought on by a light flashing repeatedly into the eyes, and musicogenic epilepsy [34] where the epileptic seizure is brought on by hearing a piece of music.

After defining and knowing the notion of reflex epilepsies, we are surprised by the fact that many mystics and artists describe in their writings cases of reflex seizures that they conceive as extraordinary experiences, but never pathological. For example, Marcel Proust narrates a psychic automatism triggered by the smell and taste of a cookie along which he experiences vivid hypermnesias [35].

\subsubsection{Self-Induced Reflex Seizures}

Another important concept of reflex epilepsies refers to the so-called self-induced reflex attack, where patients 
voluntarily trigger the attack after learning how to use the adequate stimulus. The patients act this way because the self-induced attack generates pleasant emotions or behaviors [36].

Now, many mystics and artists have learned to use adequate stimuli, especially music and colored lights, to trigger reflex seizures which elicit ecstatic experiences in their minds. Herman Hesse describes the following reflex automatism in his novel Steppenwolf:

It was at a concert of lovely old music. After two or three notes of the piano the door was opened of a sudden to the other world. I sped through heaven and saw God at work. I suffered holy pains. I dropped all my defenses and was afraid of nothing in the world. I accepted all things and to all things I gave up my heart. It did not last very long, a quarter of an hour perhaps [37].

Besides, most of us are sensitive to music, which triggers sudden and automatic ecstatic experiences in us that can be compared to a reflex seizure with psychic content. In this regard, there are many psychological and musicological researches suggesting that the ecstatic emotions that arise from listening to a piece of music are experiences that many normal people have had [38]. P. Juslin [39] places ecstatic emotions that suggest automatic emotional discharges in $19^{\text {th }}$ place out of a list of 44 emotions stimulated by music in a population of normal listeners, and ordered by frequency.

\subsubsection{Reflex Seizures Triggered by Complex Stimuli}

Another important point about reflex epilepsies necessary to deal with for our proposal is the fact that reflex seizures are not only triggered by simple physical or chemical stimuli (light, sound, smell, taste, hot, cold, etc.) but also by more complex situations. Indeed, a reflex seizure can be triggered by a word, a song, a memory, etc. It seems that in all these cases the true stimulus generating the seizure is its strong affective connotation [40]. Frequently, the seizure triggered by these emotional stimuli consists in a pleasant or ecstatic experience, in such a way that the subject learns how to use the adequate stimulus in order to get a self-induced seizure. On this point, Pontius and Wiese [40] reported 23 cases of these pleasant behavioral seizures and proposed that affective memories could replace in humans the physical stimuli necessary for kindling in primates.

Following this trend, many mystics have learned to use some words (mantras and/or invocations) as adequate stimuli to generate illuminative and ecstatic states in their minds.

So, after reviewing reflex epilepsies, there are new evidences that reinforce our hypothesis: not only mystics, artists, and philosophers recount episodes of pleasant reflex automatisms when they listen to a piece of music or when they evoke words with strong affective connotations, but many of us have experienced the same ecstatic feelings with similar stimuli.

\subsection{Findings on Epileptogenesis}

At this stage, we decided to carry out a study on the current knowledge of the electrochemical brain mechanisms of epileptogenesis. According to Sloviter [8], we use this concept to encompass the primary process that causes principal neurons to generate their first spontaneous, multiple population spike-containing epileptiform discharges, whether or not they produce any clinical manifestation.

This analysis provided us with plenty of new information reinforcing the hypothesis that our brain uses neuronal hypersynchrony as an adaptive tool to perform the functions necessary to the survival of individuals and species. We can group these new pieces of information in four blocks:

1) Onset of the epileptic firing as a physiological process;

2) Close relationship between neuronal hypersynchrony and learning;

3) Close relationship between neuronal hypersynchrony and sexuality;

4) Existence of opposite types of hypersynchronous activities.

\subsubsection{Onset of the Epileptic Firing as a Physiological Process}

Leading epilepsy specialists have suggested the possibility that the beginning of the epileptic process could be physiological: certain areas of the brain (hippocampus, entorhinal and piriform cortex, cerebral amygdala) seem to be constitutionally and physiologically prepared to fire in hypersynchronously. On this point, Philip Schwartzkroin states, "The activity that we call epilepsy, then, may reflect a basic underlying propensity of the central nervous system" [41]. Likewise, Massimo Avoli says: "The patterns of activity generated by neurons in the human epileptogenic cortex appear in most instances to be remarkably normal” [42]. 
In the same line, these cerebral areas are the most likely to react to two well known physiological hypersynchronies: Kindling and long-term-potentiation (LTP) [43].

So, there are evidences that support that the initial burst of epilepsy might have a physiological nature.

\subsubsection{Close Relationship between Neuronal Hypersynchrony and Learning}

Curiously, the areas that are most sensitive to LTP are also the most plastic of our brain, a plasticity that is closely linked with learning and memory. In this regard, Schwartzkroin highlights the paradoxical relationship between LTP's plasticity and learning:

Is it simply coincidence that cortical regions-brain areas clearly involved in normal learning and experience-dependent behavior and thus presumably "plastic"-are the most common sites of epileptic abnormalities? One could argue that the mechanisms that are responsible for the plasticity underlying normal behavior are just those features that support epileptiform activities [41].

Therefore, it seems that the neuronal hypersynchronous answer to repetitive stimuli is the mechanism our brain uses to record data from experience. It should come as no surprise, then, that Michel Baudry suggested "the possibility that epilepsy may represent a dangerous side-effect of an efficacious learning mechanism" [44]. Here we have, literally, the same hypothesis that we are defending: a hypersynchronous firing conceived as the expression of an efficient cerebral functioning.

\subsubsection{Close Relationship between Neuronal Hypersynchrony and Sexuality}

Another indicative argument to the physiologic nature of certain kinds of neuronal hypersynchronies is the close relationship with sexuality, and more specifically, between epilepsy and orgasm.

On one hand, orgasm is the psychic experience occurring during sexual climax and, curiously, it has all the phenomenological characteristics of SPS: it is sudden, passive, and very intense, and it appears with a feeling of strangeness caused by something very strong and vivid that automatically invades the consciousness. On the other hand, there is an increasing body of clinical and electroencephalographic evidence that orgasm-induced seizures are not infrequent in patients with SPSs, sometimes of reflex nature [36] [45].

Janice Stevens links this hypersynchronous firing to sexuality as a communication method of our brain to transmit messages necessary for the survival of the individual and of the specie:

Manifest by intense brainstem and forebrain discharges that occur in sleep and in relation to ovulation, lactation, and sexual climax, the spike mode of message transmission guarantees delivery of information vital to the survival of the species, but it also carries the risk of seizures or psychosis if wide propagation occurs [46].

\subsubsection{Existence of Opposite Kinds of Hypersynchronous Activities}

Traditionally bursts have been considered as pro-epileptic and precursors of ictal seizures, but there are also indications suggesting that both activities are opposed and mutually exclusive, as Wilson and Bragdon state:

Moreover, although epileptiform bursts can trigger electrographic seizures, their main effect may be to suppress seizures arising in their target areas. Thus interictal spikes in humans may have a suppressive effect on seizure discharges [47].

In the same vein, epileptologists have split ictal activity into two different kinds of hypersynchronies: localized seizures and propagated seizures, which seem to have different natures and different aims, as stated by Gale:

In fact, the ability to evoke local seizure discharge within a structure is unrelated to the ability to provoke a propagated seizure. Focal drug stimulation in certain brain areas can evoke local electrographic seizure discharge without evoking a propagated seizure, whereas in other regions partial drug stimulation can evoke propagated seizures without first evoking local seizure discharge [48].

So, there are evidences suggesting that these two kinds of activities are not only different and mediated by different neuroreceptors, but mutually exclusive at the same time [47]-[49].

\subsection{Psychic Hypersynchrony}

We have now enough information to explain in detail how to conceive the automatic experiences that have been described above. We think that these hypersynchronies, in so far they remain limited to their original areas, must be interpreted as adaptive behaviors. Until now the psychic manifestations of these hypersynchronies was conceived as a result of an impairment of consciousness and, thus, as pathological events. But, according to our hy- 
pothesis, they should be interpreted as a consequence of a superior organization of consciousness which has not pathological nature.

We propose to name this adaptive function psychic hypersynchrony (PH). This new term has been decided for two reasons: first, the fact that this innovative hypothesis entails great consequences that will lead to important changes in different neurosciences: neurology, psychiatry, neurophysiology, etc. Basically and in short, it is necessary to clearly distinguish the PH from epileptic hypersynchrony, since the second has a pathological connotation.

Then, PH is a cerebral function that has been insufficiently delimited until now. We conceive this function as a sophisticated tool of our brain that developing progressively. All of us have this physiological hypersynchronous ability to a lesser or greater extent. But, as we have checked along our writing, this ability is more developed in some groups of people, a fact that denotes the evolutionary and hereditary nature of this function.

The most frequent psychic event appearing in PH is the sudden impression of having acquired a new and unexpected intuitive knowledge, which is considered absolutely true by the subject. This conviction can be so strong that it can be accompanied by the feeling of clairvoyance. This fact points out that PH is related with intuitive knowledge. Furthermore, the person often interprets these sudden and clairvoyant intuitions as coming from an external and alien mind, different from their own consciousness, which explains why he thinks to have experienced telepathic phenomena.

PH is probably a still unstable function, in such way that when it gets too intense it derails and spreads to other cortex areas not suitable to $\mathrm{PH}$, causing a propagated epileptic hypersynchrony.

All these defining features of $\mathrm{PH}$, just described above, appear very well summarized in the famous "final second" of Fedor Dostoyevsky in The Idiot:

He remembered that during his epileptic fits, or rather immediately preceding them, he had always experienced a moment or two when his whole heart, and mind, and body seemed to wake up to vigor and light; when he became filled with joy and hope, and all his anxieties seemed to be swept away for ever; these moments were but presentiments, as it were, of the one final second (it was never more than a second) in which the fit came upon him. That second, of course, was inexpressible [50].

\section{Discussion}

The hypothesis of PH entails important and innovative consequences regarding some neuroscientific disciplines, especially on psychiatry, neurology and neuro-psycho-pharmacology.

\subsection{Innovative Consequences on Psychiatry}

First, the PH hypothesis implies an important change in the conception of a great number of mental illnesses. Certainly, many symptoms and syndromes conceived until now as psychiatric disorders from now on should be considered as expression of a physiological function of the brain. They should be interpreted as psychiatric disorders only when these hypersynchronous phenomena cause a morbid way of life with psychosocial impairment.

In the same vein, several authors defend that psychopathological phenomena are not enough to constitute a psychiatric illness. That there must be a coexistence of social and/or moral consequences so that these psychic manifestations can be considered mental illnesses [51] [52]. We are of the same opinion: we can only diagnose a psychiatric disorder when hyperic manifestations cause social or working deterioration on the subject experiencing them, that is, a sickly way of life.

A second major consequence of this model is that psychiatry loses almost all its legal character. Therefore, from now psychic hypersynchronies can not be used as insanity defense [53], leading to the disappearance of most hospitalizations and/or forced psychiatric treatments.

PH has also important consequences on psychiatric taxonomy. From this new approach, the psychiatric classification would comprise two main groups of mental disorders: a big group of psychiatric disorders coming from $\mathrm{PH}$, and a second big group in which predominate negative and defective symptoms such autism, schizophrenia with predominance of negative symptoms, dementia, etc.

\subsection{Innovative Consequences on Epilepsy}

The PH hypothesis affects the conception and taxonomy of epilepsies. Until now, SPSs with psychic manifesta- 
tions were a kind of epileptic seizure, but from now they should be conceptualized as an adaptive activity of our brain. There can be other types of adaptive hypersynchronies different from $\mathrm{PH}$, such as sensitive, motor, or vegetative hypersynchronies. In this regard, the Jacksons's interpretation of sneeze as "a sort of healthy epilepsy,” [1] comes immediately to our memory. However, our study remains focused on PH and refrains from the analysis of no psychic hypersynchronies.

\subsection{Innovative Explanation of Relationship between Epilepsy and Psychosis}

Another important consequence of PH is that it helps to understand the paradoxical relationship between epilepsy and psychosis, which was unexplained until now. On the one hand, there is irrefutable evidence that brings out the high co-occurrence of epilepsy and schizophrenia [54], epilepsy and major depressive disorder [22], and epilepsy and bipolar disorder [26] [27].

On the other hand, there are also strong clinical evidences that suggest that the processes are antagonistic and mutually exclusive in time. On this enigmatic relationship between epilepsy and psychosis, M.S. Starr summarizes the problem:

One of the great unresolved medical controversies of the twentieth century concerns the relationship between epilepsy and psychosis. Limbic structures are suspected of being intimately involved in the pathophysiology of both neurological conditions, but for more than a century medical thinkers have failed to agree upon whether these two common disorders are closely associated, unrelated, or mutually antagonistic to one another [55].

Now we can offer a natural answer to this paradoxical relationship: epileptic hypersynchrony and psychic hypersynchrony are not only different, but also antagonistic, because the purpose of the first one is to suppress the second. This fact allows us to easily explain some questions which have not been answered thus far:

1) Why does the epileptic activity of the EEG stop only when psychosis appears? And, conversely, why does it start again when psychosis comes to an end?

2) In the same lines, why does an epileptic seizure bring an end to an acute psychosis, a frequently observed clinical fact?

3) And, finally, why is electro-convulsive therapy, after one hundred years of use, still valid for stopping psychotic experiences?

These three questions have one and the same answer: psychic and epileptic hypersynchronies are activities that cannot appear at the same time because one's presence implies the suppression of the other.

\subsection{Innovative Consequences on Neuropsychopharmacology}

The hypothesis of PH also enables us to answer other important questions, this time in the field of neuropsychopharmacology.

Firstly, why anticonvulsant drugs are effective in many psychiatric disorders, such as alcohol and benzodiazepine withdrawal syndromes, panic and anxiety disorders, dementia, schizophrenia, affective disorders, bipolar affective disorders in particular, and, to some extent, personality disorders? [56]. The answer to this question emerges obviously from our hypothesis: they are all substances that reduce neuronal excitability and so placate all kinds of neuronal hypersynchronies, included PH.

The same can be said for antidepressant drugs, which are also used to suppress depressive phases and panic attacks, phenomena that our hypothesis put down to PH. The reason is exactly the same: they act as anticonvulsants, decreasing neuronal excitability and the subsequent hypersynchronous experiences. When we suggested the anticonvulsant role of antidepressants for the first time, more than ten years ago [57], it was against the beliefs of the majority of neurologists and psychiatrists. In fact, the proconvulsant role of antidepressants, both tricyclics and SSRIs, was a generally assumed fact in clinical practice. But along the last decade appeared investigations obviously defending this position [58], a fact that reinforces our hypothesis.

Similarly, when we posited the anticonvulsant role of antipsychotics it was very difficult to find investigations supporting it. In fact, at that time antipsychotic substances were mainly interpreted as proconvulsant and epileptic seizures were one of the side-effects of these drugs. However, during the last two decades a new pharmacological hypothesis of schizophrenia has been expanding: the glutamate hypothesis, which agrees with our approach regarding the anticonvulsant role of antipsychotic drugs [59]. Therefore, antipsychotic drugs seem to act inhibiting and placating $\mathrm{PH}$, as we suggested more than ten years ago [57]. 


\section{Conclusions}

PH should be considered a cerebral cognitive function consisting in a spontaneous depolarization of a great number of neurons at the same time, which generates an epileptiform discharge. The psychic manifestations due to this epileptiform activity, interpreted until present as of pathological nature, are conceived from now as physiological and productive signs of this cognitive function, being this fact the most innovative corollary of this hypothesis.

This proposal allows us to clarify and fit many pieces of information belonging to different neuroscientific fields (neurophysiology, neurology, psychiatry, neuropsychopharmacology, etc.) which have been, until now, confusing or paradoxical.

In this sense, this approach constitutes a new paradigm in the sense that Thomas S. Kuhn [60] gives to this term: on one hand, it makes possible to fit in some neuroscientific pieces of information in a comprehensible set that the current paradigm does not allow us to explain. On the other hand, the new explanation forces us to reject some information that was until now conceived as true and reliable by the neuroscientific community.

From now on, it is necessary to develop psychological tolls which can objectify this cognitive function. At this regard, a rating scale is being elaborated in order to determine the level of PH [61].

\section{Conflict of Interests}

None.

\section{References}

[1] Temkin, O. (1971) The Falling Sickness. The Johns Hopkins University Press, Baltimore \& London.

[2] Womelsdorf, T., Schoffelen, J.M., Oostenveld, R., Singer, W., Desimone, R., et al. (2007) Modulation of Neuronal Interactions through Neuronal Synchronization. Science, 316, 1609-1612. http://dx.doi.org/10.1126/science.1139597

[3] Álvarez, J. (1997) Mística y depresión: San Juan de la Cruz. Editorial Trotta, Madrid

[4] Álvarez, J. (2000) Éxtasis sin Fe. Editorial Trotta, Madrid.

[5] Alvarez-Silva, S., Alvarez-Rodriguez, J. and Cavanna, A.E. (2012) Epileptic Aura and Qualitative Consciousness in Focal Seizures: A Neuropsychiatric Approach. Epilepsy \& Behavior, 23, 512-513. http://dx.doi.org/10.1016/j.yebeh.2011.11.031

[6] Alvarez-Silva, S., Alvarez-Silva, I., Alvarez-Rodriguez, J., Perez-Echeverria, M.J., Campayo-Martinez, A. and RodríguezFernandez, F.L. (2006) Epileptic Consciousness: Concept and Meaning of Aura. Epilepsy \& Behavior, 8, 527-533. http://dx.doi.org/10.1016/j.yebeh.2005.12.013

[7] Alvarez-Rodriguez, J., Alvarez-Silva, S. And Alvarez-Silva, I. (2005) Epilepsy and Psychiatry: Automatic Psychic Paroxysms. Medical Hypotheses, 65, 671-675. http://dx.doi.org/10.1016/j.mehy.2005.03.030

[8] Sloviter, R.S., Bumanglag, A.V., Schwarcz, R.M. and Frotscher, M. (2012) Abnormal Dentate Gyrus Network Circuitry in Temporal Lobe Epilepsy. In: Noebels, J., Avoli, M., Rogawski, M., Olsen, R. and Delgado-Escueta, A., Eds., Jasper's Basis Mechanisms of the Epilepsies, Oxford University Press, New York, 454-469.

[9] St. John of the Cross (1952) Dark Night of the Soul. Translated by E. Allison Peers, Chistian Classics Ethereal Library. http://www.ccel.org/ccel/john_cross/dark_night.txt

[10] St. John of the Cross (1952) Ascent of Mount Carmel. Translated by E. Allison Peers. http://www.ccel.org/ccel/john_cross/ascent.txt

[11] Saint Ignatius Loyola (1990) The Autobiography of St. Ignatius. Translated by J. O’Conor. http://www.basilica.org/pages/ebooks/St.\%20Ignatius-The\%20Autobiography\%20of\%20Ignatius.pdf

[12] Vercelletto, P. (1994) Saint Paul Disease. Ectasia and Extatic Seizures. Revue Neurologique, 150, 835-839.

[13] Meissner, W. (1994) Ignatius of Loyola: The Psychology of a Saint. Yale University Press, New Haven.

[14] García-Albea, E. (1995) Teresa de Jesús: Una ilustre epiléptica. Fundación Wellcome y Hospital Universitario Príncipe de Asturias, Alcalá de Henares.

[15] Berg, A.T., Berkovic, S.F., Brodie, M.J., Buchhalter, J., Cross, J.H., van Emde Boas, W., et al. (2010) Revised Terminology and Concepts for Organization of Seizures and Epilepsies: Report of the ILAE Commission on Classification and Terminology. Epilepsia, 51, 676-685. http://dx.doi.org/10.1111/j.1528-1167.2010.02522.x

[16] Kinnier Wilson, S.A. (1928) Modern Problems in Neurology. Edward Arnold, London.

[17] Ey, H. (1954) Études Psychiatriques. Desclée de Brouwer, Paris. 
[18] Devinsky, O. and Luciano, D. (1991) Psychic Phenomena in Partial Seizures. Seminars in Neurology, 11, 100-111. http://dx.doi.org/10.1055/s-2008-1041211

[19] Gerez, M., Sada, A. and Tello, A. (2011) Amygdalar Hyperactivity, a Fear-Related Link between Panic Disorder and Mesiotemporal Epilepsy. Clinical EEG and Neuroscience, 42, 29-39. http://dx.doi.org/10.1177/155005941104200108

[20] Paparrigopoulos, T., Tzavellas, E., Karaiskos, D., Liappas, I. and Kyrozis, A. (2008) Left Parieto-Occipital Lesion with Epilepsy Mimicking Panic Disorder. Progress in Neuro-Psychopharmacology and Biological Psychiatry, 2, 16061608.

[21] Bob, P., Jasova, D. and Raboch, J. (2011) Subclinical Epileptiform Process in Patients with Unipolar Depression and Its Indirect Psychophysiological Manifestations. PLoS ONE, 6, 28041. http://dx.doi.org/10.1371/journal.pone.0028041

[22] Kanner, A.M. (2008) Depression and Epilepsy: A New Perspective on Two Closely Related Disorders. Epilepsy Currents, 6, 141-146. http://dx.doi.org/10.1111/j.1535-7511.2006.00125.x

[23] Alvarez-Silva, I., Alvarez-Rodriguez, J., Alvarez-Silva, S., Perez-Echeverria, M.J. and Campayo-Martínez, A. (2007) Melancholic Major Depression and Epilepsy. Medical Hypotheses, 69, 1046-1053. http://dx.doi.org/10.1016/j.mehy.2007.01.088

[24] Landtblom, A.M., Lindehammar, H., Karlsson, H. and Craig, A.D. (2011) Insular Cortex Activation in Patient with Sensed Presence/Ecstatic Seizures. Epilepsy \& Behavior, 20, 714-718. http://dx.doi.org/10.1016/j.yebeh.2011.01.031

[25] Picard, F. and Craig, A.D. (2009) Ecstatic Epileptic Seizures: A Potential Window on the Neural Basis for Human Self-Awareness. Epilepsy \& Behavior, 16, 539-546. http://dx.doi.org/10.1016/j.yebeh.2009.09.013

[26] Mula, M., Marotta, A.E. and Monaco, F. (2010) Epilepsy and Bipolar Disorders. Expert Review of Neurotherapeutics, 10, 13-23. http://dx.doi.org/10.1586/ern.09.139

[27] Mazza, M., Nicola, M., Della Marca, G., Janiri, P. and Mazza, S. (2007) Bipolar Disorder and Epilepsy: A Bidirectional Relation? Neurobiological Underpinnings, Current Hypotheses, and Future Research Directions. Neuroscientist, 13, 392-404. http://dx.doi.org/10.1177/10738584070130041101

[28] Alvarez-Silva, I., Alvarez-Silva, S. and Alvarez-Rodriguez, J. (2010) Positive Syndrome of Schizophrenia and Epilepsy. Medical Hypotheses, 74, 294-296. http://dx.doi.org/10.1016/j.mehy.2009.09.004

[29] Kasper, B.S., Kasper, E.M., Pauli, E. and Stefan, H. (2010) Phenomenology of Hallucinations, Illusions, and Delusions as Part of Seizure Semiology. Epilepsy \& Behavior, 18, 13-23. http://dx.doi.org/10.1016/j.yebeh.2010.03.006

[30] Elliot, B., Joyce, E. and Shorvon, S. (2009) Delusions, Illusions and Hallucinations in Epilepsy: 2. Complex Phenomena and Psychosis. Epilepsy Research, 85, 172-186. http://dx.doi.org/10.1016/j.eplepsyres.2009.03.017

[31] St. Agustine Confessions-Book One. http://www.ourladyswarriors.org/saints/augcon1.htm

[32] Beaumanoir, A., Gastaut, H. and Naquet, R. (1989) Reflex Seizures and Reflex Epilepsies. Editions Médicine et Hygiène, Paris.

[33] Harding, A. and Jeavons, P.M. (1994) Photosensitive Epilepsy. Mac Keith Press, London.

[34] Critchley, M. and Henson, R.A. (1977) Music and the Brain. William Heinemann Medical Books Limited, London.

[35] Proust, M. (1982) Remembrance of Things Past. Volume 1: Swann’s Way: Within a Budding Grove. Vintage Books, New York. http://www.haverford.edu/psych/ddavis/p109g/proust.html

[36] Sengupta, A., Mahmoud, A., Tun, S.Z. and Goulding, P. (2010) Orgasm-Induced Seizures: Male Studied with Ictal Electroencephalography. Seizure, 19, 306-309. http://dx.doi.org/10.1016/j.seizure.2010.04.007

[37] Hesse, H. (1963) Steppenwolf. Holt, Rinehart and Winston, Carlsbad. http://img0.liveinternet.ru/images/attach/c/0/3716/3716962_hermann_hesse_steppenwolf.pdf

[38] Penman, J. and Becker, J. (2009) Religious Ecstatics, “Deep Listeners”, and Musical Emotion. Empirical Musicology Review, 4, 49-70.

[39] Juslin, P. (2005) From Mimesis to Catharsis: Expression, Perception, and Introduction of Emotion in Music. In: Miell, D., MacDonald, R. and Hargreaves, D.J., Eds., Musical Communication, Oxford University Press, New York, 85-109. http://dx.doi.org/10.1093/acprof:oso/9780198529361.003.0005

[40] Pontius, A.A. and Wieser, H.G. (2004) Can Memories Kindle Nonconvulsive Behavioral Seizures in Humans? Case Report Exemplifying the “Limbic Psychotic Trigger Reaction”. Epilepsy \& Behavior, 5, 775-783. http://dx.doi.org/10.1016/j.yebeh.2004.05.013

[41] Schwartzkroin, P.A. (2007) Epilepsy: Models, Mechanisms and Concepts. Cambridge University Press, New York.

[42] Avoli, M. (2007) Electrophysiology and Pharmacology of Human Neocortex and Hippocampus in Vitro. In: Schwartzkroin, P.A., Ed., Epilepsy: Models, Mechanisms and Concepts, Cambridge University Press, New York, 244-280. 
[43] Cain, D.P. (1989) Long-Term Potentiation and Kindling: How Similar Are the Mechanisms? Trends in Neuroscience, 12, 6-10. http://dx.doi.org/10.1016/0166-2236(89)90146-X

[44] Baudry, M. (1986) Long-Term Potentiation and Kindling: Similar Biochemical Mechanisms? In: Delgado-Escueta, A.V., Ward, A.A, Woodbury, D.M. and Poeter, R.J., Eds., Basic Mechanisms of the Epilepsies: Molecular and Cellular Approaches, Raven Press, New York, 401-410.

[45] Ozkara, C., Ozdemir, S., Yilmaz, A., Uzan, M., Yeni, N. and Ozmen, M. (2006) Orgasm-Induced Seizures: A Study of Six Patients. Epilepsia, 47, 193-197. http://dx.doi.org/10.1111/j.1528-1167.2006.00648.x

[46] Stevens, J. (1986) All That Spikes Is Not Fits. In: Trimble, M.R. and Reynolds, E.H., Eds., What Is Epilepsy? Churchill Livingstone, London, 97-115.

[47] Wilson, W.A. and Bragdon, A. (1993) Brain Slice Models for the Study of Seizures and Interictal Spikes. In: Schwartzkroin, P.A., Ed., Epilepsy: Models, Mechanisms and Concepts, Cambridge University Press, New York, 371387. http://dx.doi.org/10.1017/CBO9780511663314.015

[48] Gale, K. (1993) Focal Trigger and Pathways of Propagation in Seizure Generation. In: Schwartzkroin, P.A., Ed., Epilepsy: Models, Mechanisms and Concepts, Cambridge University Press, New York, 48-93.

[49] Uva, L., Librizzi, L., Wendling, F. and De Curtis, M. (2005) Propagation Dynamics of Epileptiform Activity Acutely Induced by Bicuculline in the Hippocampal-Parahippocampal Region of the Isolated Guinea Pig Brain. Epilepsia, 46, 1914-1925. http://dx.doi.org/10.1111/j.1528-1167.2005.00342.x

[50] Dostoievski, F. (1992) The Idiot. Oxford University Press, New York. http://www.online-literature.com/dostoevsky/idiot/21/

[51] Fuldford, K.W. (2011) Neuroscience and Values: A Case Study Illustrating Developments in Policy, Training and Research in the UK and Internationally. Mens Sana Monographs, 9, 79-92. http://dx.doi.org/10.4103/0973-1229.77428

[52] Kinghorn, W.A. (2011) Whose Disorder? A Constructive MacIntyrean Critique of Psychiatric Nosology. Journal of Medicine and Philosophy, 36, 187-205. http://dx.doi.org/10.1093/jmp/jhr006

[53] Appelbaum, P.S. (2013) Law \& Psychiatry: Does the Constitution Require an Insanity Defense? Psychiatric Services, 64, 943-945. http://dx.doi.org/10.1176/appi.ps.6401004

[54] Cascella, N.G., Schretien, D.J. and Sawa, A. (2009) Schizophrenia and Epilepsy: Is There a Shared Susceptibility? Neuroscience, 63, 227-235.

[55] Starr, M.S. (1996) The Role of Dopamine in Epilepsy. Synapse, 22, 159-194. http://dx.doi.org/10.1002/(SICI)1098-2396(199602)22:2<159::AID-SYN8>3.0.CO;2-C

[56] Kaufman, K.R. (2012) Antiepileptic Drugs in the Treatment of Psychiatric Disorders. Epilepsy \& Behavior, 21, 1-11. http://dx.doi.org/10.1016/j.yebeh.2011.03.011

[57] Álvarez, J. (2001) Neuronal Hypersynchronization, Creativity and Endogenous Psychoses. Medical Hypotheses, 56, 672-685. http://dx.doi.org/10.1054/mehy.2000.1269

[58] Jobe, C. and Browning, R.A. (2005) The Serotonergic and Noradrenergic Effects of Antidepressant Drugs Are Anticonvulsant, Not Proconvulsant. Epilepsy \& Behavior, 7, 602-619. http://dx.doi.org/10.1016/j.yebeh.2005.07.014

[59] Sendt, K.V., Giarolly, G. and Tracy, D.K. (2012) Beyond Dopamine: Glutamate as a Target for Future Antipsychotics. ISRN Pharmacology, 2012, Article ID: 427267.

[60] Kuhn, T.S. (1962) The Structure of Scientific Revolutions. Chicago University Press, Chicago.

[61] Alvarez-Rodriguez, J. (2013) Hyperia Rating Scale. http://www.newpsychiatry.com/article?c_art=148 
Scientific Research Publishing (SCIRP) is one of the largest Open Access journal publishers. It is currently publishing more than 200 open access, online, peer-reviewed journals covering a wide range of academic disciplines. SCIRP serves the worldwide academic communities and contributes to the progress and application of science with its publication.

Other selected journals from SCIRP are listed as below. Submit your manuscript to us via either submit@scirp.org or Online Submission Portal.
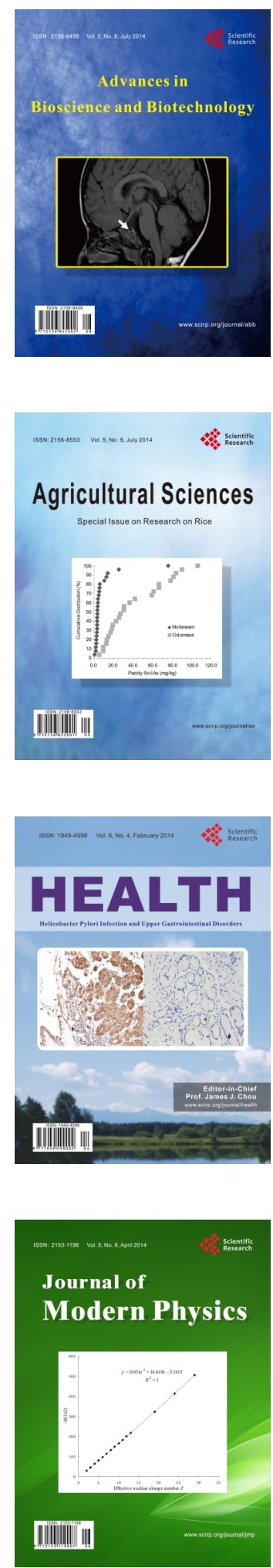
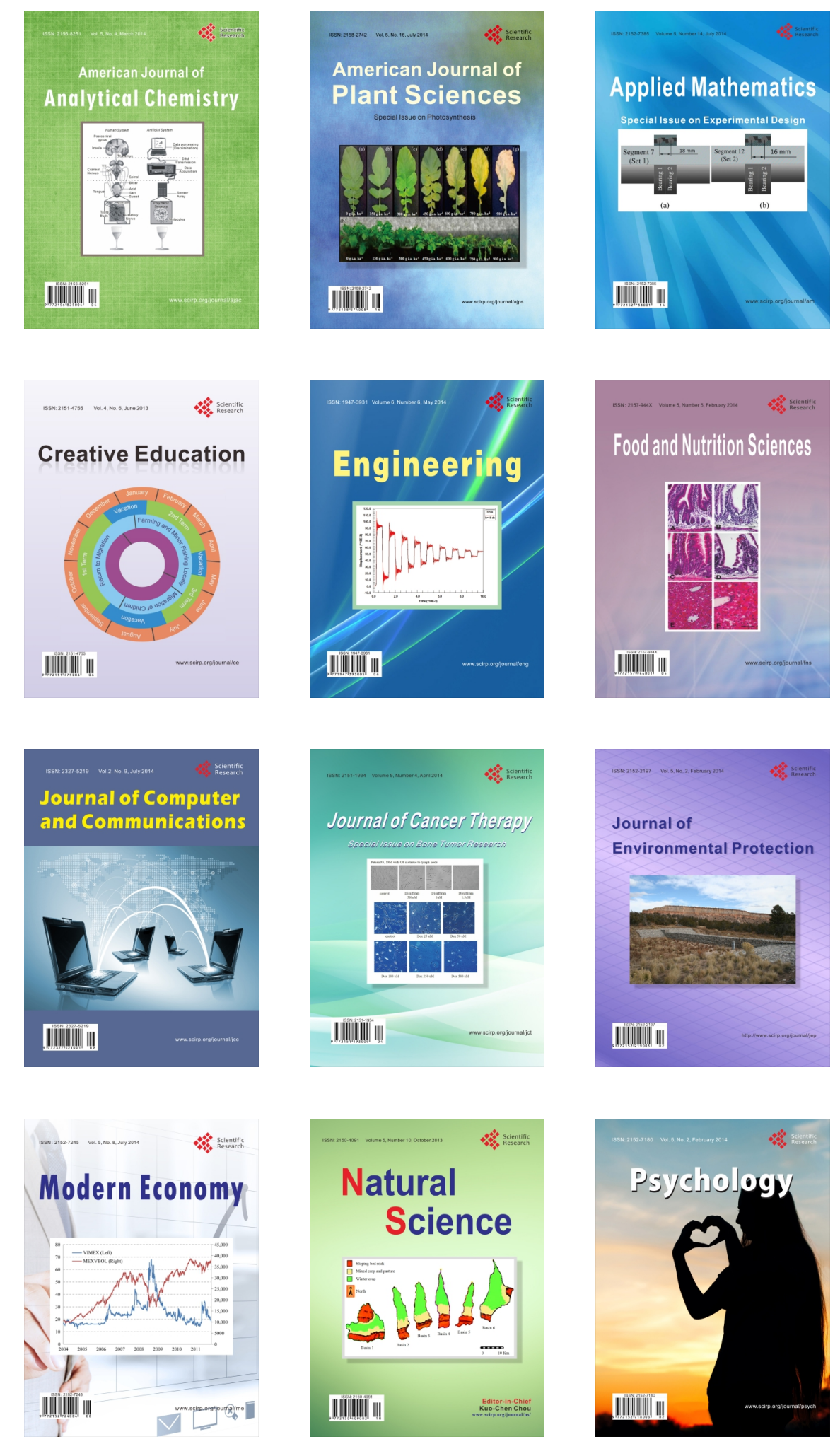